\title{
Tin-carboxylate MOFs for sugar transformation into methyl
}

\section{lactate}

Beatriz Murillo, ${ }^{1}$ Beatriz Zornoza, ${ }^{1,2}$ Oscar de la Iglesia, ${ }^{1,3}$ Sujing Wang, ${ }^{4}$ Christian Serre, ${ }^{3}$ Carlos Téllez, ${ }^{1}$ Joaquín Coronas ${ }^{1, *}$

${ }^{1}$ Chemical and Environmental Engineering Department, Instituto de Nanociencia de Aragón (INA) and Instituto de Ciencia de Materiales de Aragón (ICMA), Universidad de Zaragoza-CSIC, 50018 Zaragoza, Spain.

${ }^{2}$ Department of Energy and Environment, Instituto de Carboquímica-ICB-CSIC, Miguel Luesma Castán 4, 50018 Zaragoza, Spain

${ }^{3}$ Centro Universitario de la Defensa Zaragoza, Academia General Militar, 50090 Zaragoza, Spain.

${ }^{4}$ Institut des Matériaux Poreux de Paris, FRE 2000 CNRS, Ecole Normale Supérieure, Ecole Supérieure de Physique et de Chimie Industrielles de Paris, PSL University Paris, 75005, France.

*Corresponding author: Joaquín Coronas. Universidad de Zaragoza. c/ Mariano Esquillor s/n. 50018 Zaragoza. Spain. Phone: 34976 762471. Fax: 34976 761879. e-mail: coronas@unizar.es

Dr. Beatriz Murillo

Dr. Beatriz Zornoza

Dr. Oscar de la Iglesia

Dr. Sujing Wang 
Prof. Dr. Christian Serre

Prof. Dr. Carlos Téllez

Prof. Dr. Joaquín Coronas 


\begin{abstract}
With the purpose of improving the production of methyl lactate (ML) from sugars (glucose and sucrose), a new metal-organic framework (MOF) denoted UZAR-S10, containing Sn ions and ligand 2-aminobenzene-1,4-dicarboxylate was synthesized. The SEM and PXRD characterization revealed that UZAR-S10 was highly crystalline. The empirical formula of UZAR-S10 is $\left[\left(\mathrm{NH}_{2}-\mathrm{BDC}\right) \mathrm{Sn}\right] \cdot\left(\mathrm{NH}_{2}-\mathrm{BDC}\right)_{0.5}$, i.e., per $\mathrm{Sn}$ atom, with one structural ligand molecule and half ligand molecule trapped in the MOF structure. The removal of the trapped ligand by either solvent extraction or thermal treatment damaged the structure of UZAR-S10, making not possible its activation. The performance of UZAR-S10 in the production of ML was compared to those achieved with different types of carboxylate MOFs, especially with that of Sn partially substituted $\mathrm{Ti}$ tetracarboxylate MOF denoted MIP-177-LT (MIP-177-LT(Ti/Sn)). The highest ML yields achieved from sucrose were $29.5 \%$ and $42.0 \%$ for UZAR-S10 and MIP-177$\mathrm{LT}(\mathrm{Ti} / \mathrm{Sn})$, respectively.
\end{abstract}

\title{
Keywords
}

Biomass, MOF catalysis, Metal-organic framework, Sugar conversion, Lactic acid 


\section{Introduction}

Biomass, storing energy from the Sun, has been always present along human being history. First, as the primary heating source through burning wood; nowadays evoking the challenge to build a more sustainable world by using biomass to obtain a large variety of chemical substances. In this context, one of the platform molecules produced from biomass is lactic acid. ${ }^{[1]}$ This molecule is the most important hydroxycarboxylic acid due to its wide range of applications in the food, cosmetics, pharmaceutical and chemical industries. ${ }^{[2]}$ Above all, the main use of this compound is in the polymer market, since lactic acid is the precursor for biocompatible and biodegradable polymer polylactic acid (PLA) that is a thermoplastic aliphatic polyester. ${ }^{[3]}$ PLA is used to make commercial products related to packaging, agriculture, transportation, electronics and houseware, among others. ${ }^{[4]}$

Industrially, ca. $90 \%$ of lactic acid is produced by the fermentation of aqueous glucose. ${ }^{[1]}$ However, this process has some drawbacks such as a long reaction time, high energy consumption and large amount of waste produced in the needed neutralization and purification steps. ${ }^{[5]}$ As an alternative to lactic acid production, several industrial routes, first based on homogeneous catalysis, were proposed from petrochemical resources, such as acetaldehyde. ${ }^{[6]}$ Moreover, research studies have reported the use of homogeneous catalysts in the production of lactic acid. ${ }^{[7,8]}$ For instance, Zhou et al. ${ }^{[7]}$ developed a method for the conversion of carbohydrates into methyl lactate using $\mathrm{SnCl}_{4}$ as catalyst. These authors used $\mathrm{NaOH}$ to neutralize the protons generated in the methanolysis of $\mathrm{SnCl}_{4}$, increasing the yield to methyl lactate. However, the used catalysts are toxic and corrosive and their recovery is difficult, so this homogeneous catalysis route is not an attractive alternative. 
Focusing on heterogeneous catalysis, where the catalysts could be recovered and reused with low cost, several solid catalysts have been applied for the conversion of sugars to lactic acid and derivatives. Different zeolites and ordered mesoporous silicas (OMSs) were used for this purpose with good results: BEA-type zeolite, ${ }^{[9-11]}$ MFI-type zeolite $^{[12]}$ FAU-type zeolite, ${ }^{[13]}$ and OMSs Sn-MCM-41 ${ }^{[12,14,15]}$ and SBA-15. ${ }^{[12]}$ In addition, other kinds of solids were applied in this reaction, such as tin-exchanged montmorillonite clay, ${ }^{[16]}$ supported noble metal catalysts, ${ }^{[17]}$ alumina supported $\mathrm{KOH}^{[18]}$ and carbon-silica composite. ${ }^{[19]}$

Recently, we tested ZIFs (zeolitic imidazolate frameworks) ZIF-8 and ZIF-67 for the conversion of sugars (glucose, fructose and sucrose) into methyl lactate. ${ }^{[20]}$ These two materials belong to a subclass of MOFs (metal organic frameworks) based on 2methylimidazolate linker and $\mathrm{Zn}$ and Co metals. In fact, there is a great interest in the use of MOF catalysts in the biorefinery field, and MOFs have been reviewed as catalytic materials in biomass upgrading to produce value-added fine chemicals. ${ }^{[21]}$ In particular, ZIF-8 was found to be the most efficient MOF for the conversion of sucrose into methyl lactate with a yield of $42 \% .{ }^{[20]}$ From these previous results and from the fact that Sn-Beta was the best performing zeolite in the pioneering related work by Holm et al., ${ }^{[9]}$ we hypothesized that a possible tin-containing MOF would be able to produce a good performance in the sugar transformation to methyl lactate. For this purpose, we investigated the synthesis of carboxylate type MOFs based on metal tin. Thus a new MOF (from now UZAR-S10) has been discovered based on the combination of tin and 2aminobenzene-1,4-dicarboxylic acid. To the best of our knowledge, this is the first time that this combination has been used to produce a MOF, even though $\mathrm{Sn}$ has been previously coordinated to create MOF type solids with phosphonates, ${ }^{[22]}$ several other dicarboxylates $^{[23]}$ and porphyrin. ${ }^{[24]}$ In addition, we studied the behavior of the mixed 
metal(IV) tetracarboxylate MOF denoted MIP-177-LT(Ti/Sn), obtained through direct synthesis by substituting $\mathrm{Sn}^{4+}$ ions into the Ti12 cluster SBU of MIP-177-LT, ${ }^{[25]}$ in the mentioned reaction.

\section{Results and discussion}

\subsection{Characterization of UZAR-S10}

Fig. 1 shows the PXRD patterns corresponding to several UZAR-S10 samples obtained at different synthesis durations from $1 \mathrm{~h}$ to $48 \mathrm{~h}$. Even if no significant change of crystallinity was found as a function of synthesis time, due to the fact that $1 \mathrm{~h}$ synthesis showed some PXRD peak intensities lower than those seem at higher times, $5 \mathrm{~h}$ was chosen as the typical synthesis time to obtain powders for characterization and catalysis application. For comparison, the PXRD pattern of $\mathrm{NH}_{2}-\mathrm{MIL}-53(\mathrm{Al})$, based on the MIL53 topology, ${ }^{[26]}$ is shown. There is no matching between UZAR-S10 and $\mathrm{NH}_{2}-\mathrm{MIL}-$ 53(Al) patterns, and as far as we know UZAR-S10 is a new phase not previously reported. However, in spite of the high crystallinity of UZAR-S10, all the attempts carried out until the moment to solve its structure were unsuccessful. The SEM images of UZAR-S1 obtained at $5 \mathrm{~h}$ (Fig. 2) depict also high crystallinity in agreement with the previous PXRD results. Sheet particles of 3-5 $\mu \mathrm{m}$ with ca. $300 \mathrm{~nm}$ thicknesses were obtained. The change of the synthesis time between 1 and $48 \mathrm{~h}$ did not produce significant changes in morphology (Fig. S1). 


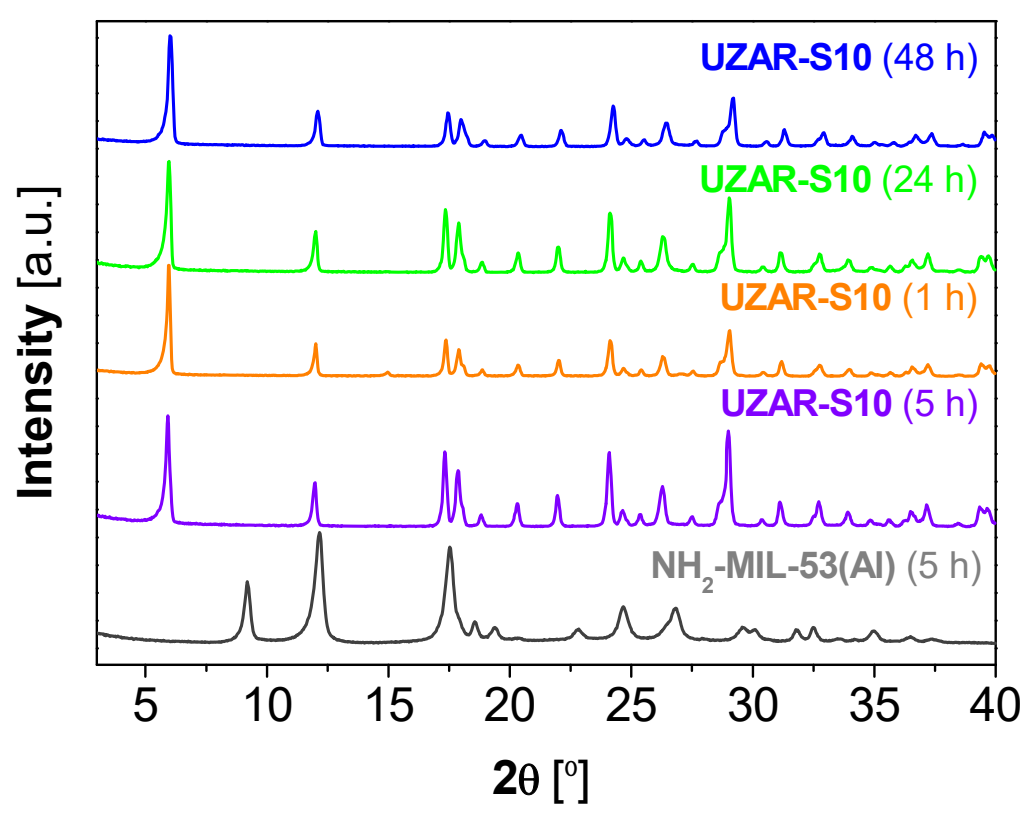

Figure 1. PXRD patterns of UZAR-S10 synthesized at $150{ }^{\circ} \mathrm{C}$ for $1-48 \mathrm{~h}$; comparison with $\mathrm{NH}_{2}-\mathrm{MIL}-53(\mathrm{Al})$ synthesized at $150{ }^{\circ} \mathrm{C}$ for $5 \mathrm{~h}$.

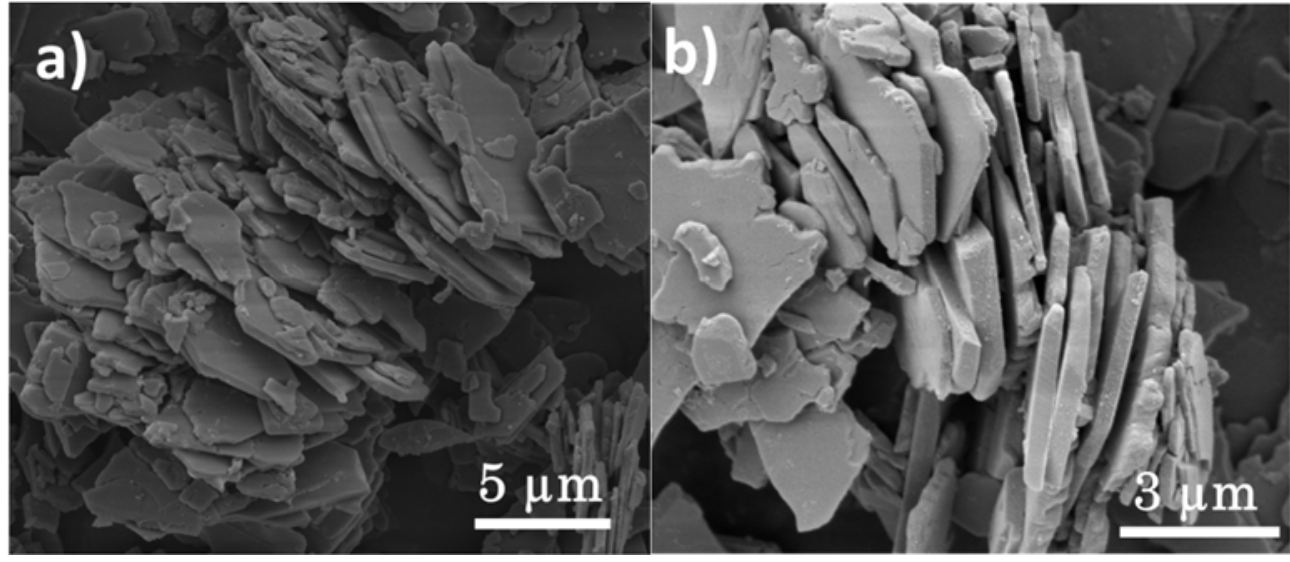

Figure 2. SEM images of UZAR-S10 synthesized at $150{ }^{\circ} \mathrm{C}$ for $5 \mathrm{~h}$ at two different magnifications.

The elemental analysis carried out on UZAR-S10 revealed wt $\%$ concentrations of 37.1 2.4 and 5.8 for $\mathrm{C}, \mathrm{H}$ and $\mathrm{N}$, respectively. This is in agreement with the atomic composition of the ligand $\mathrm{NH}_{2}-\mathrm{H}_{2} \mathrm{BDC}$, probing that its nature was not modified upon the solvothermal synthesis of the material. As shown in Fig. 3, there is a first loss of weight $(22 \%)$ until $330{ }^{\circ} \mathrm{C}$ that is attributed to organic linker molecules trapped in the eventual 
porosity of the MOF. Between 330 and $550{ }^{\circ} \mathrm{C}$, the loss of weight (44\%) is due to coordinated organic linker. Finally, the remain after $550{ }^{\circ} \mathrm{C}(34 \%)$ corresponds to $\mathrm{SnO}_{2}$. This information and the previous statement about the preservation of the linker was used to estimate the empirical formula of UZAR-S10 as follows: [( $\left.\left.\mathrm{NH}_{2}-\mathrm{BDC}\right) \mathrm{Sn}\right] \cdot\left(\mathrm{NH}_{2}-\right.$ BDC) $)_{0.5}$, i.e. $\mathrm{C}_{24} \mathrm{H}_{14} \mathrm{O}_{12} \mathrm{~N}_{3} \mathrm{Sn}_{2}$, with one structural linker molecule and half linker molecule trapped in the MOF structure per Sn atom.

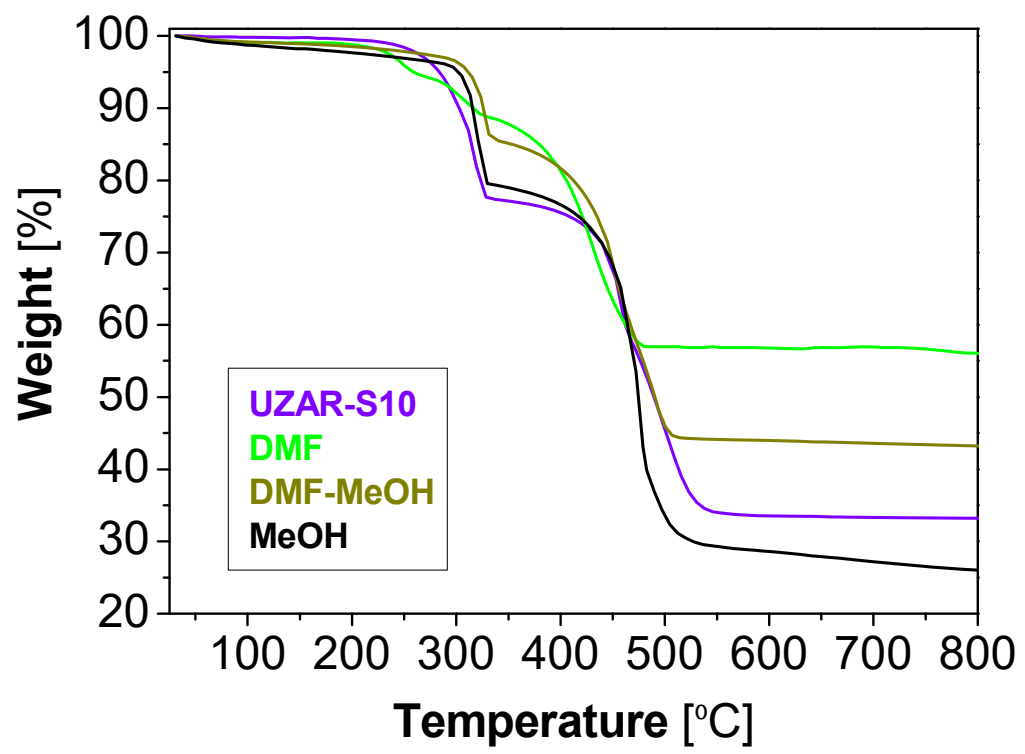

Figure 3. TGA curves in air of UZAR-S 10 synthesized at $150{ }^{\circ} \mathrm{C}$ for $5 \mathrm{~h}$ upon treatment with different solvents.

A problematic issue regards the activation of UZAR-S10. Neither the immersion in methanol at $70{ }^{\circ} \mathrm{C}$ for $15 \mathrm{~h}$ or in DMF at $150^{\circ} \mathrm{C}$ for $15 \mathrm{~h}$ nor that in DMF $\left(150{ }^{\circ} \mathrm{C}\right.$ for 15 h) followed by methanol at $70{ }^{\circ} \mathrm{C}$ for $15 \mathrm{~h}$ produced the desired activation, giving rise to materials with respective BET specific surface areas of 6,23 and $39 \mathrm{~m}^{2} / \mathrm{g}$ (see the corresponding $\mathrm{N}_{2}$ isotherms in Fig. S2). As shown in Fig. 3, these immersions, particularly when carried out in DMF, reduced somehow the $330^{\circ} \mathrm{C}$ step of loss of weight while increased that assigned to $\mathrm{SnO}_{2}$, in parallel producing a clear decrease in crystallinity (Fig. S3). In other words, UZAR-S10 seems to be stable in methanol but not 
in DMF and the loss of part of the half molecule of ligand trapped, see the above discussed empirical formula, triggered the degradation of the material. To gain insight into the MOF thermal stability and possible thermal activation, UZAR-S10 was submitted to thermodifractometry under vacuum up to $300{ }^{\circ} \mathrm{C}$, conditions that clearly deteriorated the crystalline structure (Fig. 4). Nevertheless, the structure was stable at $275^{\circ} \mathrm{C}$. This was corroborated by the PXRD patterns obtained at room temperature upon heating at increasing temperatures $\left(200,250,275,300,325\right.$ and $\left.400{ }^{\circ} \mathrm{C}\right)$ for $8 \mathrm{~h}$, as shown in Fig. S4a. Interestingly, as the treatment temperature increased, the ca. $330{ }^{\circ} \mathrm{C}$ step of loss of weight was reduced to the point that at $300{ }^{\circ} \mathrm{C}$ when the PXRD was clearly damaged it almost disappeared (Fig. S4b).

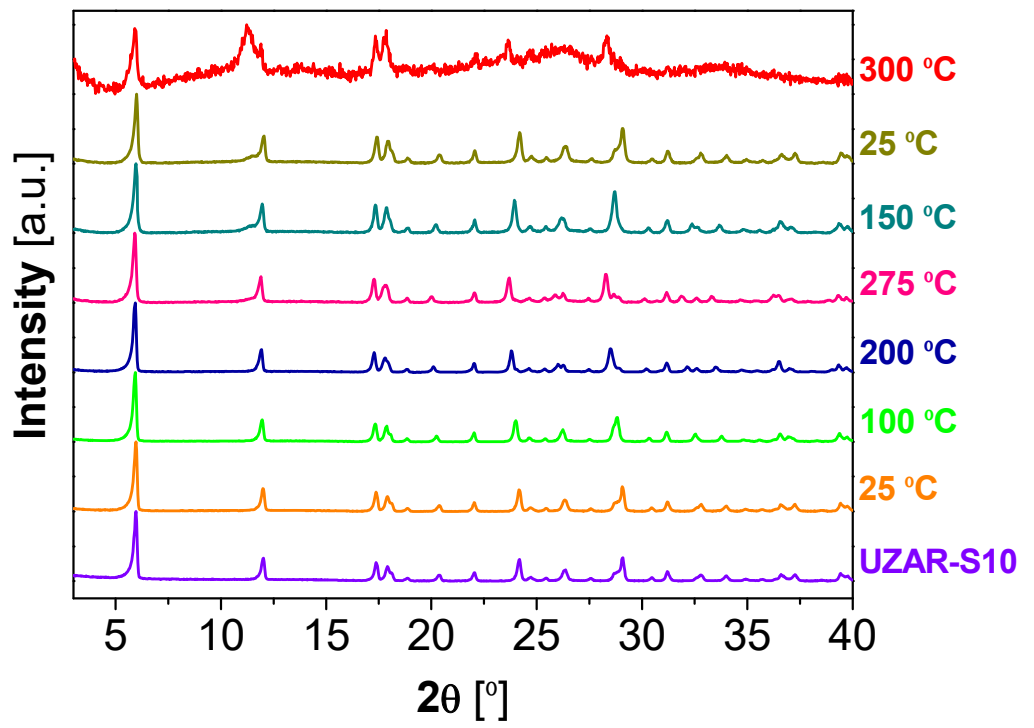

Figure 4. Thermodiffractometry carried out under vacuum maintaining the sample at each condition for $10 \mathrm{~min}$, starting at $25^{\circ} \mathrm{C}$ (bottom) and finishing at $300{ }^{\circ} \mathrm{C}$ (top); after $275{ }^{\circ} \mathrm{C}$ the temperature was decreased to 150 and $25{ }^{\circ} \mathrm{C}$ and then increased to $300{ }^{\circ} \mathrm{C}$. UZAR-S10 obtained at $150{ }^{\circ} \mathrm{C}$ for $5 \mathrm{~h}$.

\subsection{Catalytic tests}


UZAR-S10 was first tested in the transformation of glucose into methyl lactate (ML) in a methanol medium. The results of the glucose conversion of this material are summarized in Table 1 and compared with the blank experiment (ML yield 1.4\%) and those of other related carboxylate type MOFs: MIL-53(Al), $\mathrm{NH}_{2}-\mathrm{MIL}-53(\mathrm{Al}), \mathrm{Zr}$ containing UiO-66, Cu containing HKUST-1 and MIL-101(Cr). UZAR-S10 reached the highest ML yield (10.2\%) and a similar total yield (i.e. including pyruvaldehyde dimethyl acetal (PADA), 1,1,2,2-tetramethoxypropane (TMP) and other non-identified products (n.i.p.)) to UiO-66 (15.1-15.5\%). Note that the sugar conversion itself was always ca. $100 \%$ in presence of catalyst; ${ }^{[15,20]}$ this is the reason because it was not systematically estimated (since such value does not contribute to the discussion). In any event, these values are below the ML (19.8\%) and total (22.7\%) yields achieved by ZIF-8 in the same conditions. ${ }^{[20]}$ The poor performance of UiO-66 can be due to the presence of metal $\mathrm{Zr}$, already demonstrated to be inferior to $\mathrm{Sn}$ when studied for sugar conversion in zeolite beta. ${ }^{[9]}$ UZAR-S10, even having the desired metal for this type of reactions, ${ }^{[9,10,15]}$ was not as efficient as expected due probably to the impossibility of activating its porosity, as shown above. In addition, it has been reported a higher Lewis acidity for $\mathrm{Zn}$ containing porous solids than for those with $\mathrm{Sn}$ in their composition, ${ }^{[27,28]}$ what would favor ZIF-8 over UZAR-S10 for the current studied reactions in this work.

Table 1. Catalytic results obtained for sugar conversion with different catalysts using glucose $\left(160^{\circ} \mathrm{C}\right.$ for $20 \mathrm{~h}, 160 \mathrm{mg}$ of catalyst and $225 \mathrm{mg}$ of glucose). Methyl lactate (ML), pyruvaldehyde dimethyl acetal (PADA), 1,1,2,2-tetramethoxypropane (TMP) and nonidentified products (n.i.p.). 


\begin{tabular}{|c|c|c|c|c|c|c|c|}
\hline \multirow{2}{*}{ Run } & \multirow{2}{*}{ Catalyst } & \multicolumn{4}{|c|}{ Yield (\%) } & \multirow{2}{*}{$\begin{array}{c}\text { Total } \\
\text { yield }(\%)\end{array}$} & \multirow{2}{*}{$\begin{array}{c}\text { Sugar } \\
\text { conv. }(\%)\end{array}$} \\
\hline & & $\overline{M L}$ & PADA & TMP & n.i.p. & & \\
\hline 1 & Blank $^{[20] ~ a ~}$ & $1.4 \pm 0.9$ & $2.5 \pm 1.4$ & $0.1 \pm 0.04$ & $4.3 \pm 1.3$ & 8.3 & 88.6 \\
\hline 2 & ZIF-8 $8^{[20]}$ & $19.8 \pm 2.6$ & $0.8 \pm 0.1$ & $0.1 \pm 0.03$ & $2.0 \pm 1.5$ & 22.7 & 98.1 \\
\hline 3 & MIL-53(Al) & $0.9 \pm 0.2$ & $1.3 \pm 0.2$ & $0.2 \pm 0.07$ & $3.3 \pm 0.2$ & 5.7 & - \\
\hline 4 & $\mathrm{NH}_{2}-\mathrm{MIL}-53(\mathrm{Al})$ & $1.9 \pm 0.2$ & $2.3 \pm 0.3$ & $0.3 \pm 0.09$ & $5.1 \pm 0.9$ & 9.6 & - \\
\hline 5 & $\mathrm{UiO}-66$ & $9.7 \pm 3.1$ & $1.4 \pm 0.7$ & $0.4 \pm 0.02$ & $4.0 \pm 1.8$ & 15.5 & - \\
\hline 6 & MIL-101(Cr) & $0.9 \pm 0.3$ & $0.7 \pm 0.02$ & $0.1 \pm 0.05$ & $2.4 \pm 0.2$ & 4.1 & - \\
\hline 7 & HKUST-1 & $0.8 \pm 0.3$ & $1.3 \pm 0.5$ & $2.2 \pm 0.2$ & $4.7 \pm 0.4$ & 9.0 & - \\
\hline 8 & UZAR-S10 & $10.2 \pm 2.3$ & $1.3 \pm 0.6$ & $0.5 \pm 0.06$ & $3.1 \pm 1.2$ & 15.1 & - \\
\hline 9 & $\begin{array}{l}\text { MIP-177- } \\
\text { LT(Ti/Sn) }\end{array}$ & $21.8 \pm 1.4$ & $2.4 \pm 0.4$ & $0.7 \pm 0.02$ & $3.1 \pm 0.1$ & 28.0 & $>99.7$ \\
\hline
\end{tabular}

${ }^{\mathrm{a}}$ Reaction time of $24 \mathrm{~h}$.

It has been reported that the thermostability and hydrolytic resistance of the disaccharide and the slow release of hexoses from sucrose in solution prevents unwanted side reactions as compared to the more reactive glucose and fructose. ${ }^{[29]}$ This explains why sucrose usually gives rise to higher methyl lactate yields than glucose. ${ }^{[9,20]}$ In consequence, UZAR-S10 was tested for the sucrose conversion to methyl lactate. Fig. 5 shows ML yields as a function of reaction time using both glucose and sucrose sugars. Maximum ML yields of $10.2 \pm 2.3 \%$ and $28.0 \pm 4.4 \%$ were achieved from glucose and sucrose at 20 and $24 \mathrm{~h}$, respectively, with some improvement at $48 \mathrm{~h}(29.5 \%)$. It is worth mentioning that these two sets of reaction conditions did not alter the crystallinity of UZAR-S10 (Fig. S5) in terms of $2 \cdot$ theta values. However, clear decreases of intensities can be observed in Fig. S5 for peaks at $17.3^{\circ}, 17.9^{\circ}, 24.1^{\circ}$ and $29.0^{\circ} 2 \cdot$ theta values. These 
decreases can be associated with the reduction of the TGA loss of weight at ca. $330{ }^{\circ} \mathrm{C}$ (Fig. S6), in line with the previous discussion where a direct relation was established between this weight loss step and structure damage in terms of PXRD. The solid treated with sucrose was washed with methanol under reflux for $15 \mathrm{~h}$ and subsequently dried overnight at $200^{\circ} \mathrm{C}$. Then, it gave rise to a BET specific surface area of only $32 \mathrm{~m}^{2} / \mathrm{g}$, in agreement with the small area values above discussed and confirming that the decrease in the $330^{\circ} \mathrm{C}$ TGA step has to be related to loss of crystallinity and not to the activation of the MOF porosity.

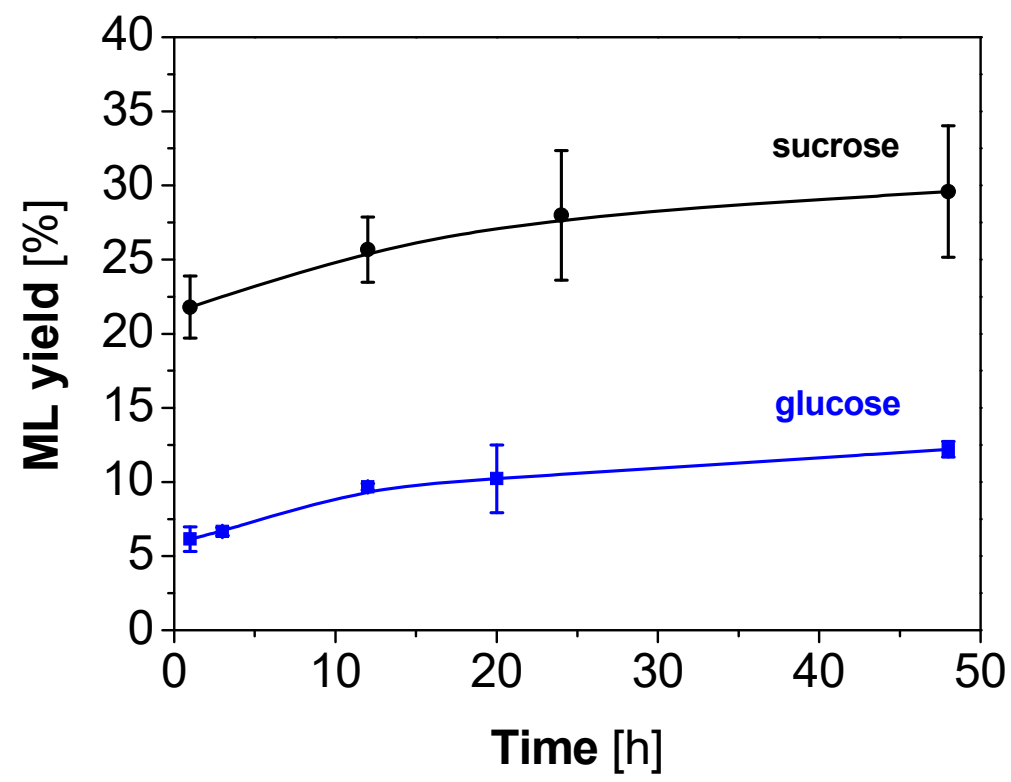

Figure 5. Yield of methyl lactate (ML) obtained with UZAR-S10 using glucose and sucrose. Error bars derived from 4 different experiments at the same conditions $\left(160{ }^{\circ} \mathrm{C}\right.$, $160 \mathrm{mg}$ of catalyst and $225 \mathrm{mg}$ of sugar).

MIP-177-LT (MIP stands for Materials from Institute of porous materials from Paris), a lately reported porous and robust Ti-MOF comprising a $\mathrm{Ti}_{12} \mathrm{O}_{15}$ cluster and a tetracarboxylate ligand delimiting a $1.1 \mathrm{~nm}$ channel type porosity, can be modified by 
replacing Ti atoms in the SBU by other metals. ${ }^{[25]}$ The successful introduction of Sn into the $\mathrm{Ti}$ oxide matrix has been demonstrated through a combination of advanced characterization techniques (see SI for more information). This has been done to obtain MIP-177-LT (Ti/Sn), a MOF that now includes in its structure a main group metal (Sn) useful for the sugar transformation reaction studied here. The results in the preliminary glucose transformation were the best among all the catalysts tested (see Table 1) with a ML yield of $21.8 \%$. In consequence, the MOF was tested with sucrose as substrate as usually gives higher ML yields than glucose.

As shown in Fig. 6 and Table S1, fresh MIP-177-LT(Ti/Sn) achieved a ML yield of $39.4 \%$ (cycle 1), which is above those obtained with UZAR-S10 (28.0\%, see Fig. 5) or with $131 \mathrm{mg}$ of $\mathrm{TiCl}_{4}$ and $21.5 \mathrm{mg}$ of $\mathrm{SnCl}_{2} \cdot 2 \mathrm{H}_{2} \mathrm{O}(26.8 \%$, see Table S1), that corresponds to the same respective amounts of metals present in MIP-177-LT(Ti/Sn), under the same conditions $\left(160^{\circ} \mathrm{C}\right.$ for $20 \mathrm{~h}, 160 \mathrm{mg}$ of catalyst and $225 \mathrm{mg}$ of sugar). The better performance of MIP-177-LT(Ti/Sn) compared to that of UZAR-S10 can be due to the more accessible porosity of MIP-177-LT(Ti/Sn). This exhibits BET specific surface area and pore volume values (see Table 2) of ca. $470 \mathrm{~m}^{2} / \mathrm{g}$ and $0.42 \mathrm{~cm}^{3} / \mathrm{g}$, respectively, in contrast to UZAR-S10 with no relevant textural properties as shown above. In fact, it has been reported a BET area of ca. $700 \mathrm{~m}^{2} / \mathrm{g}$ for the only Ti-containing MOF MIP177. ${ }^{[25]}$ The discrepancy between MIP-177-LT(Ti) and MIP-177-LT(Ti/Sn) BET area values could be due partially to the heavier atomic weight of $\mathrm{Sn}$ compared to $\mathrm{Ti}$, since same total porous volume or surface area values would produce lower specific values for similar porous structures prepared with weightier components. In any event, the catalytic activity of these solids is related to the presence of Lewis acid sites, active for the carbohydrate transformation to ML as proposed for different catalysts, such as Sn salts, ${ }^{[8]}$ Sn-zeolites, ${ }^{[11]} \mathrm{Sn}-\mathrm{MCM}-41^{[15]}$ and Zr-SBA-15, ${ }^{[30]}$ In the case of MOFs, these Lewis acid 
sites would come from the presence of metals (e.g. Sn) bearing such sites $^{[31]}$ without discarding Brønsted acidity ${ }^{[32]}$ generated by the grafting of water or methanol molecules to unsaturated metal sites. ${ }^{[33]}$

The catalyst was submitted to five successive reaction cycles at the same conditions (Fig. 6 and Table S1). After the first cycle the catalyst showed an increase in performance and the second cycle gave rise to a ML yield of $42.0 \%$. This could be explained by an extra activation of the MOF during the sugar transformation in the methanol medium. In agreement with this, some stabilization was reached after the third cycle with a ML yield of $30.2 \%$, similar to those achieved after the fourth (30.2\%) and last fifth $(33.4 \%)$ cycle. After four sucrose conversion cycles in the same operation conditions, ZIF-8 showed a ML yield of $27.2 \% .{ }^{[20]}$ Table 2 shows the BET specific surface area and pore volume values as a function of reaction cycle, obtained from the $\mathrm{N}_{2}$ adsorption isotherms in Fig. S7. The BET area decreased to $85-112 \mathrm{~m}^{2} / \mathrm{g}$ after any of the reaction cycles in line with the adsorption of some of the species involved in the reaction. ${ }^{[20]}$ ZIF- 8 showed a decrease in the BET area from 1390 to $760 \mathrm{~m}^{2} / \mathrm{g}$ after the fourth reaction cycle with sucrose. ${ }^{[20]}$ The porosity of MIP-177-LT presents large channels with free diameter of $1.1 \mathrm{~nm},{ }^{[25]}$ more inclined to fouling with reaction species, due to facilitated access, than the $0.34 \mathrm{~nm}$ pores of ZIF-8, ${ }^{[34]}$ even if it is true that ZIF-8 presents the phenomenon of gate opening ${ }^{[35]}$ and can allow the hosting of bulkier molecules such as caffeine ${ }^{[36]}$ Run cycle $1 \mathrm{~b}$ in Table $\mathrm{S} 1$, that corresponds to a run in which, with the used catalyst from cycle 1, no sugar was added to the reactor, demonstrated that some reaction species were retained by the catalyst during the reaction. In fact, the catalyst was "activated" during this run and the BET specific surface area increased up to $250 \mathrm{~m}^{2} / \mathrm{g}$. Table 2 shows also the Ti and $\mathrm{Sn}$ compositions of MIP-177-LT(Ti/Sn) as determined by XRF. Ti content was stabilized or slightly diminished, while some loss of Sn was detected. This could contribute to the 
lower catalytic activity in cycles 3-5 as compared to the fresh catalyst (cycle 1). In any event, the crystallinity of the catalyst (see Fig. S8) was not altered upon the reaction cycles carried out, and after five cycles the XRD pattern obtained resembled well that corresponding to the fresh catalyst.

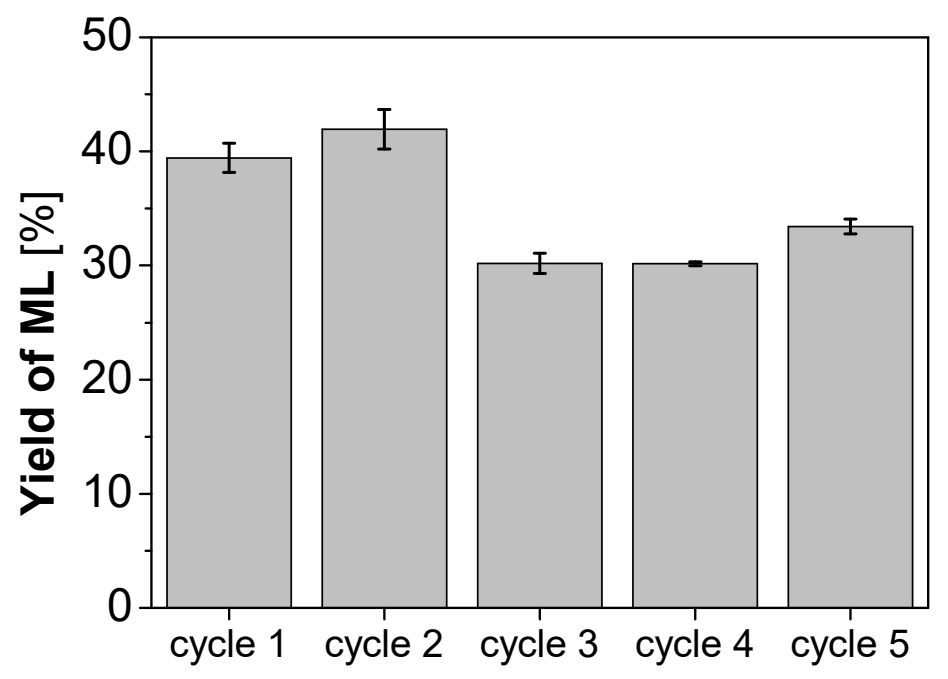

Figure 6. Yield of methyl lactate (ML) obtained with MIP-177-LT(Ti/Sn) using sucrose $\left(160{ }^{\circ} \mathrm{C}\right.$ for $24 \mathrm{~h}, 160 \mathrm{mg}$ of catalyst and $225 \mathrm{mg}$ of sugar). Error bars derived from 5 different experiments (cycle 1), 4 different experiments (cycle 2), 3 different experiments (cycle 3), 2 different experiments (cycle 4) and 3 analyses from 1 experiment (cycle 5).

Table 2. Results of the analysis of titanium and tin by X-ray fluorescence (XRF) in catalyst MIP-177-LT(Ti/Sn) before reaction and after 1, 3 and 5 cycles of reaction (see Fig. 6). With the used catalyst from cycle 1 , cycle $1 \mathrm{~b}$ corresponds to a run in which no sugar was added to the reactor. 


\begin{tabular}{lcccc}
\hline Sample & $\begin{array}{c}\text { BET surface } \\
{\left[\mathrm{m}^{2} / \mathrm{g}\right]}\end{array}$ & $\begin{array}{c}\text { Pore volume } \\
{\left[\mathrm{cm}^{3} / \mathrm{g}\right]^{\mathrm{a}}}\end{array}$ & Ti (wt.\%) & Sn (wt.\%) \\
\hline MIP-177- & $466 \pm 5$ & 0.42 & $20 \pm 0.1$ & $6.9 \pm 0.2$ \\
LT(Ti/Sn) & $95 \pm 1$ & 0.18 & $19 \pm 0.1$ & $6.6 \pm 0.1$ \\
Cycle 1 & $250 \pm 1$ & 0.33 & - & - \\
Cycle 1b & $109 \pm 1$ & 0.18 & - & - \\
Cycle 2 & $85 \pm 1$ & 0.17 & $18 \pm 0.2$ & $5.9 \pm 0.2$ \\
Cycle 3 & $89 \pm 1$ & 0.16 & - & - \\
Cycle 4 & $112 \pm 1$ & 0.15 & $18 \pm 0.3$ & $5.6 \pm 0.1$ \\
Cycle 5 & & & & \\
\hline
\end{tabular}

${ }^{a}$ At 0.96 of relative pressure.

\section{Conclusions}

A new MOF (UZAR-S10) with the empirical formula of $\left[\left(\mathrm{NH}_{2}-\mathrm{BDC}\right) \mathrm{Sn}\right] \cdot\left(\mathrm{NH}_{2}-\right.$ BDC) 0.5 was synthesized with the aim of improving the MOF performance in the transformation of glucose and sucrose into methyl lactate. UZAR-S10 is a crystalline material consisting of sheet like crystals of 3-5 $\mu \mathrm{m}$ with ca. $300 \mathrm{~nm}$ thicknesses and contains one structural ligand molecule and half ligand molecule trapped in the MOF structure per Sn atom. The attempts to activate this material by solvent extraction with methanol, DMF or sequences of both did not produce a satisfactory result, even though the above mentioned half ligand molecule trapped in the MOF porosity suggested a high porosity. The highest BET specific surface area value measured was $39 \mathrm{~m}^{2} / \mathrm{g}$. In fact, the removal of that half ligand molecule by either solvent extraction of thermal treatment damaged the structure of UZAR-S10, making not possible its activation. 
When compared in terms of glucose conversion to methyl lactate at the same reaction conditions $\left(160{ }^{\circ} \mathrm{C}\right.$ for $20 \mathrm{~h}$ using $160 \mathrm{mg}$ of catalyst and $225 \mathrm{mg}$ of sugar), the methyl lactate yield of UZAR-S10 (10.2\%) was better than those of the benchmark MOFs MIL-53(Al), $\mathrm{NH}_{2}-\mathrm{MIL}-53(\mathrm{Al}), \mathrm{HKUST}-1$ and MIL-101(Cr), similar to that UiO-66 (9.7\%) and lower than that of ZIF-8 (19.8\%). However, the methyl lactate yield achieved with UZAR-S10 using sucrose instead of glucose was, at the best tested conditions (160 ${ }^{\circ} \mathrm{C}$ for $48 \mathrm{~h}$ using $160 \mathrm{mg}$ of catalyst and $225 \mathrm{mg}$ of sugar), $29.5 \%$, not far from the best value of $34.8 \%$ reached in our previous work with ZIF-8. Finally, the highest value of methyl lactate yield (42.0\%) was obtained from sucrose with MIP-177-LT(Ti/Sn), a MOF prepared by Sn metal exchange from the newly reported Ti tetracarboxylate MIP-177LT, that maintained a methyl lactate yield of $33.4 \%$ after five successive reaction runs. These results confirm that the presence of $\mathrm{Sn}$ in the MOF is of paramount importance to achieve a high yield to methyl lactate.

\section{Experimental}

\subsection{Synthesis of MOFs}

A new method has been developed to synthesize a Sn-carboxylate MOF called UZAR-S10 from $\mathrm{SnCl}_{2} \cdot 2 \mathrm{H}_{2} \mathrm{O}$ and $\mathrm{NH}_{2}-\mathrm{H}_{2} \mathrm{BDC}$ (2-aminobenzene-1,4-dicarboxylic acid, Sigma Aldrich, 99\%). The precursor dispersion had a molar ratio of $\mathrm{Sn}^{2+}: \mathrm{NH}_{2}-$ $\mathrm{H}_{2} \mathrm{BDC}: \mathrm{H}_{2} \mathrm{O}=1: 0.25: 136$. A typical synthesis of UZAR-S10 is as following. Firstly, 1.50 g of $\mathrm{NH}_{2}-\mathrm{H}_{2} \mathrm{BDC}$ (99\% purity, Sigma-Aldrich) was dissolved in $10 \mathrm{~mL}$ of deionized water. Secondly, $1.84 \mathrm{~g}$ of $\mathrm{SnCl}_{2} \cdot 2 \mathrm{H}_{2} \mathrm{O}$ (98 \%, Sigma-Aldrich) was dissolved in $10 \mathrm{~mL}$

of deionized water. Each solution was stirred individually for 5-10 min after which the solution containing the metal precursor was added to the linker solution. The mixture was 
transferred to a Teflon vessel (that of a $45 \mathrm{~mL}$ Teflon-lined stainless steel autoclave) and outgassed at room temperature in an ultrasound bath for $15 \mathrm{~min}$. The synthesis reaction took place at $150{ }^{\circ} \mathrm{C}$ for $5 \mathrm{~h}$. The product obtained was recovered by centrifugation at $10000 \mathrm{rpm}$ for $10 \mathrm{~min}$, washed twice with deionized water by centrifugation under the same conditions and dried at $100{ }^{\circ} \mathrm{C}$ for $24 \mathrm{~h}$. MIP-177-LT(Ti/Sn) was synthesized following the directions given in. ${ }^{[25]}$

\subsection{Catalytic reaction}

The sugar conversion to methyl lactate was carried out in a batch reactor, a $35 \mathrm{~mL}$ Teflon-lined stainless steel autoclave. Glucose (99\%, Alfa-Aesar) and sucrose (99\%, Fluka) were chosen as representative carbohydrates due to their low cost, purity, simplicity and abundance. The reaction was performed by dissolving $225 \mathrm{mg}$ of carbohydrate in $8.0 \mathrm{~g}$ of methanol (HPLC grade, Scharlau). Besides, $30 \mathrm{mg}$ of naphthalene (99\%, Sigma-Aldrich) was added as internal standard for subsequent quantification of the yields. The amount of catalyst added was $160 \mathrm{mg}$. The mixture with the sugar totally dissolved was transferred to a $45 \mathrm{~mL}$ Teflon-lined stainless steel autoclave and the synthesis was carried out in an oven. The oven was heated with a ramp of $1 \mathrm{~h}$ up to $160^{\circ} \mathrm{C}$. The reaction time $(24 \mathrm{~h})$ starts when the reaction temperature is reached under rotating conditions (15 r.p.m, i.e. the whole autoclave rotates perpendicularly to its axial axis). These conditions used to transform the sugars in the presence of solid catalysis were based on our previous reports. ${ }^{[15,20]}$

Afterwards, the catalyst was recovered by centrifugation and the reaction liquid was analyzed by gas chromatography with a mass detector (GC-MS). The equipment was an Agilent $6850 \mathrm{GC}$ system with a capillary column HP-5MS (30 m x $0.250 \mathrm{~mm}$ x $0.25 \mu \mathrm{m})$ coupled with an Agilent 5975 MSD. The yields of the different products were calculated 
using the internal standard method and calibration curves using commercial compounds: methyl-S-(-)-lactate (98\%, Sigma-Aldrich), methylglyoxal 1,1-dimethylacetal (97\%, Sigma-Aldrich), also called pyruvaldehyde dimethyl acetal, and 1,1,2,2tetramethoxypropane (99\%, Sigma-Aldrich).

The determination of sugars was carried out using a commercial analytical method (Sucrose/Fructose/D-Glucose Assay Kit, Megazyme). The analysis was carried out as follows: firstly, the sugar samples were mixed with a solution which contains enzymes (different for each sugar), these enzymes transform sugars to glucose-6-phosphate (G-6P), and reaction lasts for a few minutes. Then another solution containing nicotinamideadenine dinucleotide phosphate $\left(\mathrm{NADP}^{+}\right)$and enzyme glucose-6-phosphate dehydrogenase (G6P-DH) was added. In the presence of this enzyme, G-6-P is oxidized by $\mathrm{NADP}^{+}$producing its reduced form (NADPH), which is measured by increasing its absorbance at $340 \mathrm{~nm}$ using a UV-Vis-NIR spectrophotometer Jasco V-670.

\subsection{Catalyst characterization}

The diffraction patterns of the samples were measured by powder X-ray diffraction (PXRD) using a D-Max Rigaku X-ray diffractometer with $\mathrm{Cu}-\mathrm{K} \alpha_{1}$ radiation $(\lambda=1.5418$ Å) and a graphite monochromator. X-ray fluorescence (XRF) analyses (using a Thermo Electron ARL ADVANT'XP equipped with a rhodium tube and UNIQUANT software) were carried out on some selected samples. Thermodiffractometry was performed under vacuum in a furnace coupled to a Siemens diffractometer with a copper anode and a graphite monochromator to select the same $\mathrm{Cu}-\mathrm{K}_{\alpha 1}$ radiation. Each PXRD pattern was recorded for $20 \mathrm{~min}$ in the $2.5-40^{\circ} 2 \theta$ range with a $0.01 \%$ s scanning rate at $25,100,150$, 200,275 and $300^{\circ} \mathrm{C}$ with a heating rate of $10^{\circ} \mathrm{C} / \mathrm{min}$. Thermogravimetric analyses (TGA) were carried out using Mettler Toledo TGA/SDTA 851e equipment. Samples were heated 
in air up to $800^{\circ} \mathrm{C}$ with a heating rate of $10^{\circ} \mathrm{C} / \mathrm{min}$. Scanning electronic microscopy (SEM) images were obtained over Pt-coated specimens using an Inspect F50 model scanning electron microscope (FEI). Nitrogen adsorption-desorption isotherms were obtained with a Micromeritics Tristar 3000. Previously, the samples were degassed at 200 ${ }^{\circ} \mathrm{C}$ for $8 \mathrm{~h}$ under vacuum. Fourier transformed infrared spectra were measured on a Bruker Vertex 70 FTIR with a deuterated triglycine sulfate (DTGS) detector and ATR Golden Gate accessory in the range $600-1,800 \mathrm{~cm}^{-1}$, with an accuracy of $4 \mathrm{~cm}^{-1}$.

\section{Acknowledgments}

Financial support from the Spanish Ministry of Economy and Competitiveness (MAT2016-77290-R) and the European Social Fund (ESF) through the Aragón Government (T43-17R) is gratefully acknowledged. The authors would like to acknowledge the University of Zaragoza for the use of the Servicio General de Apoyo a la Investigación-SAI and the Laboratorio de Microscopías Avanzadas (LMA) at INA.

\section{References}

[1] M. Dusselier, P. Van Wouwe, A. Dewaele, E. Makshina, B. F. Sels, Energ. Environ. Sci. 2013, 6, 1415-1442.

[2] F. A. Castillo Martinez, E. M. Balciunas, J. M. Salgado, J. M. Domínguez González, A. Converti, R. P. d. S. Oliveira, Trends Food Sci. Tech. 2013, 30, 7083; R. Datta, M. Henry, J. Chem. Tech. Biotech. 2006, 81, 1119-1129.

[3] S. Inkinen, M. Hakkarainen, A. C. Albertsson, A. Sodergard, Biomacromolecules 2011, 12, 523-532; A. P. Gupta, V. Kumar, Eur. Polym. J. 2007, 43, 4053-4074.

[4] W. S. Chow, E. L. Teoh, J. Karger-Kocsis, Express Polym. Lett. 2018, 12, 396417. 
[5] R. P. John, A. G.S, K. M. Nampoothiri, A. Pandey, Biotech. Adv. 2009, 27, 145152.

[6] Y. J. Wee, J. N. Kim, H. W. Ryu, Food Tech. Biotech. 2006, 44, 163-172.

[7] L. Zhou, L. Wu, H. Li, X. Yang, Y. Su, T. Lu, J. Xu, J. Mol. Catal. A: Chem. 2014, 388-389, 74-80.

[8] Y. Hayashi, Y. Sasaki, Chem. Commun. 2005, 2716-2718.

[9] M. S. Holm, S. Saravanamurugan, E. Taarning, Science 2010, 328, 602-605.

[10] M. S. Holm, Y. J. Pagan-Torres, S. Saravanamurugan, A. Riisager, J. A. Dumesic, E. Taarning, Green Chem. 2012, 14, 702-706.

[11] E. Taarning, S. Saravanamurugan, M. S. Holm, J. Xiong, R. M. West, C. H. Christensen, ChemSusChem 2009, 2, 625-627.

[12] C. M. Osmundsen, M. S. Holm, S. Dahl, E. Taarning, Proc. Math. Phys. Eng. Sci. 2012, 468, 2000-2016.

[13] P. P. Pescarmona, K. P. F. Janssen, C. Delaet, C. Stroobants, K. Houthoofd, A. Philippaerts, C. De Jonghe, J. S. Paul, P. A. Jacobs, B. F. Sels, Green Chem. 2010, 12, 1083-1089; R. M. West, M. S. Holm, S. Saravanamurugan, J. Xiong, Z. Beversdorf, E. Taarning, C. H. Christensen, J. Catal. 2010, 269, 122-130.

[14] L. Li, X. Collard, A. Bertrand, B. F. Sels, P. P. Pescarmona, C. Aprile, J. Catal. 2014, 314, 56-65; L. Li, C. Stroobants, K. F. Lin, P. A. Jacobs, B. F. Sels, P. P. Pescarmona, Green Chem. 2011, 13, 1175-1181.

[15] B. Murillo, A. Sanchez, V. Sebastian, C. Casado-Coterillo, O. de la Iglesia, M. P. Lopez-Ram-de-Viu, C. Tellez, J. Coronas, J. Chem. Tech. Biotech. 2014, 89, 13441350.

[16] J. Wang, Y. Masui, M. Onaka, Appl. Catal. B: Environ. 2011, 107, 135-139. 
[17] A. Onda, T. Ochi, K. Kajiyoshi, K. Yanagisawa, Appl. Catal. A: Gen. 2008, 343, 49-54.

[18] G. Epane, J. C. Laguerre, A. Wadouachi, D. Marek, Green Chem. 2010, 12, 502506.

[19] F. de Clippel, M. Dusselier, R. Van Rompaey, P. Vanelderen, J. Dijkmans, E. Makshina, L. Giebeler, S. Oswald, G. V. Baron, J. F. M. Denayer, P. P. Pescarmona, P. A. Jacobs, B. F. Sels, J. Am. Chem. Soc. 2012, 134, 10089-10101.

[20] B. Murillo, B. Zornoza, O. de la Iglesia, C. Tellez, J. Coronas, J. Catal. 2016, 334, 60-67.

[21] A. Herbst, C. Janiak, CrystEngComm 2017, 19, 4092-4117.

[22] A. Clearfield, Dalton Trans. 2008, 6089-6102.

[23] X. Q. Wang, L. M. Liu, T. Makarenko, A. J. Jacobson, Cryst. Growth Des. 2010, 10, 3752-3756; A. C. Wibowo, M. D. Smith, H. C. zur Loye, Solid State Sci. 2011, $13,607-615$.

[24] M. H. Xie, X. L. Yang, C. Zou, C. D. Wu, Inorg. Chem. 2011, 50, 5318-5320.

[25] S. J. Wang, T. Kitao, N. Guillou, M. Wahiduzzaman, C. Martineau-Corcos, F. Nouar, A. Tissot, L. Binet, N. Ramsahye, S. Devautour-Vinot, S. Kitagawa, S. Seki, Y. Tsutsui, V. Briois, N. Steunou, G. Maurin, T. Uemura, C. Serre, Nat. Commun. 2018, 9.

[26] S. Bourrelly, P. L. Llewellyn, C. Serre, F. Millange, T. Loiseau, G. Ferey, J. Am. Chem. Soc. 2005, 127, 13519-13521.

[27] E. A. Alarcón, A. L. Villa, C. Montes de Correa, Microporous Mesoporous Mater. 2009, 122, 208-215.

[28] W. Dong, Z. Shen, B. Peng, M. Gu, X. Zhou, B. Xiang, Y. Zhang1, Sci. Rep. 2016, 26713. 
[29] M. Dusselier, B. F. Sels, in Selective Catalysis for Renewable Feedstocks and Chemicals, Vol. 353 (Ed.: K. M. Nicholas), Springer International Publishing, 2014, pp. 85-125.

[30] L. S. Yang, X. K. Yang, E. Tian, V. Vattipalli, W. Fan, H. F. Lin, J. Catal. 2016, 333, 207-216.

[31] F. Gandara, B. Gornez-Lor, E. Gutierrez-Puebla, M. Iglesias, M. A. Monge, D. M. Proserpio, N. Snejko, Chem. Mater. 2008, 20, 72-76; R. Srirambalaji, S. Hong, R. Natarajan, M. Yoon, R. Hota, Y. Kim, Y. H. Ko, K. Kim, Chem. Commun. 2012, $48,11650-11652$.

[32] A. Herbst, A. Khutia, C. Janiak, Inorg. Chem. 2014, 53, 7319-7333.

[33] A. Vimont, H. Leclerc, F. Mauge, M. Daturi, J. C. Lavalley, S. Surble, C. Serre, G. Ferey, J. Phys. Chem. C 2007, 111, 383-388.

[34] K. S. Park, Z. Ni, A. P. Cote, J. Y. Choi, R. D. Huang, F. J. Uribe-Romo, H. K. Chae, M. O'Keeffe, O. M. Yaghi, Proc. Natl. Acad. Sci. U S A 2006, 103, 1018610191.

[35] D. Fairen-Jimenez, S. A. Moggach, M. T. Wharmby, P. A. Wright, S. Parsons, T. Duren, J. Am. Chem. Soc. 2011, 133, 8900-8902.

[36] N. Liedana, A. Galve, C. Rubio, C. Tellez, J. Coronas, ACS Appl. Mater. Interfaces 2012, 4, 5016-5021. 


\section{Table of Contents Entry}

New MOF type material UZAR-S10 ([( $\left.\left.\left.\mathrm{NH}_{2}-\mathrm{BDC}\right) \mathrm{Sn}\right] \cdot\left(\mathrm{NH}_{2}-\mathrm{BDC}\right) 0.5\right)$, i.e., and MOF MIP-177-LT(Ti/Sn) applied to the production of methyl lactate from sugars.

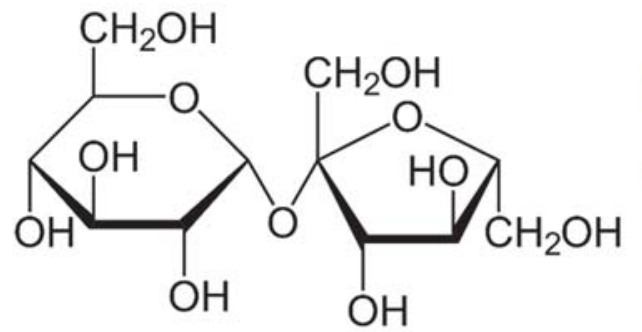

\section{Sn-carboxylate}

MOF<smiles>COC(=O)C(C)O</smiles> 